\section{Analysis of mathematical model for osseous factors in difficult intubation}

Peter Charters MD MRCP FRCA BA
A two-dimensional model of the factors relevant to difficult laryngoscopy was analysed mathematically to determine clinical implications and limitations. The model describes the space into which the "inevitable residual volume" of the tongue (that part remaining anterior to the blade at laryngoscopy) can be displaced to permit a view of the larynx. Four points are used: the tip of the upper incisors; a point on the anterior airway just above the larynx; the mid-point between the mandibular condyles and the internal mid-point of the symphysis. The number, $F$, was defined by a formula developed from their spacial relationships. Decreasing $F$ values imply an increasing likelihood of difficult laryngoscopy. The analysis investigated the effects of: translation of individual points; plotting individual point positions for specified F-values; translating adjacent pairs of points; treating any three points as a triangle which rotates about each of its apices; and lastly, translating three points independently. During manipulations the model behaved well mathematically. Single point analysis implied that jaw recession and a non-protruding mandible were comparable in effect. Closing the mouth around the laryngoscope blade maximised F-values. Prominence of the maxilla required greater forward displacement than backward movement of the symphysis for equivalent $F$-value change. One particular triangular rotation suggested an entirely novel mechanism for difficulty (the "hi-slung mandible") where the condyles are positioned more rostral than normal. An otherwise normal jaw with this configuration recedes markedly on opening. Further studies are required to validate the model. Accurate quantification of individual factors in difficult laryngoscopy may then be feasible.

\section{Key words}

ANATOMY: airway, larynx, mandible; EQUIPMENT: laryngoscopes; INTUBATION: tracheal.

From the Department of Anaesthesia, Aintree Hospitals NHS Trust, Walton Hospital, Rice Lane, Liverpool L9 1AE, UK. Address correspondence to: Dr. P. Charters. Accepted for publication 16th March, 1994.
Un modèle bi-dimensionnel propre aux facteurs pertinents à la laryngoscopie difficile est analysé mathématiquement dans le but de determiner ses applications cliniques et ses limites. Le modèle décrit l'espace dans lequel le volume résiduel de la langue (la partie excédentaire de la langue antérieure à la lame du layrngoscope) peut être déplacé pour permettre la vision du larynx. On utilise quatre points: l'extrémité des incisives supérieures; un point situé dans les voies aériennes antérieures juste aú-dessus du larynx; un point médian situé entre les condyles mandibulaires; et, finalement, le point médian de la symphyse. Le nombre $F$ est défini par une formule développée à partir de leur relation spatiale. La diminution les valeurs du $F$ signifie une laryngoscopie difficile probable. L'analyse étudie les effets de la translation des points individuels; la transposition des points individuels pour des valeurs données de F; la translation de paires de points adjacentes; la transformation d'un des trois points comme un triangle qui pivote sur chacun de ces sommets et finalement la translation individuelle de chacun des points. Le modèle se comporte très bien pendant ces manipulations. L'analyse des point isolés laisse supposer que la récession de la mâchoire et l'absence de protusion du mandibule ont un effet identique. La fermeture de la bouche sur le laryngoscope augmente les valeur du $F$. La prominence de la mâchoire nécessite un déplacmenet antérieur plus grand que le morvement postérieur de la symphyse pour des valeurs equivalentes $d u F$. Une rotation triangulaire particulière suggère un mécanisme de difficulté entièrement nouveau (le mandibule haut suspendu) lorsque les condyles occupent une position plus rostrale que la normale. Avec cette configuration, une mâchoire ordinairement normale se rétracte considérablement à louverture. Des études supplémentaires sont nécessaires pour valider ce modèle. Une quantification des facteurs individuels particuliers à la laryngoscopie difficile deviendrait alors réalisable.

Two important fundamental elements in the underlying causes and mechanisms for difficult intubation have received emphasis recently. They are the "Ease of Intubation Angle" described by Horton et al. ${ }^{1}$ and the distance from the chin to the thyro-hyoid cartilage which has received support in the study by Frerk. ${ }^{2}$ The first complements 


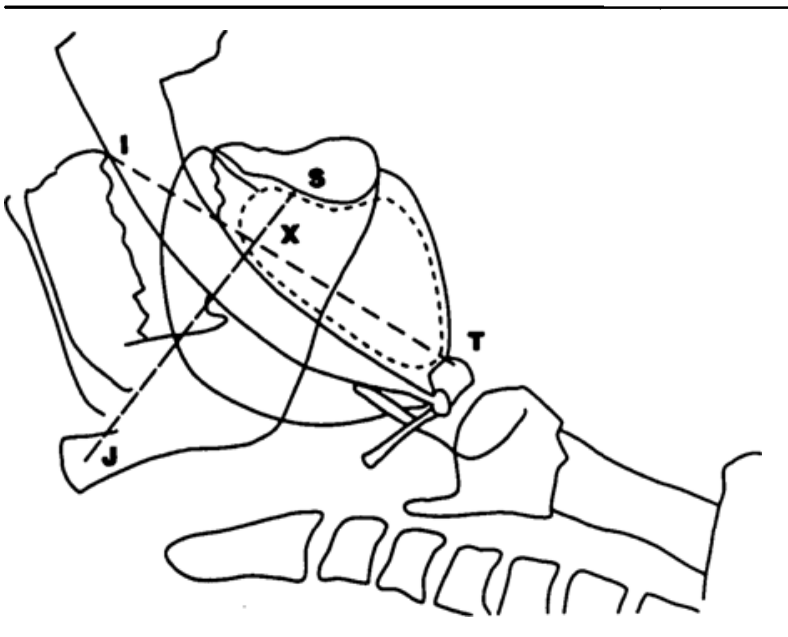

FIGURE 1 Normal disposition of the tongue IRV (inevitable residual volume) and the points I, J, S, T and X used for the analysis.

Reproduced from an $x$-ray of a subject, whose trachea was not difficult to intubate, and taken in the standard intubation position. The IRV is the dotted outline anterior to the blade.

the work by Bellhouse and Dore ${ }^{3}$ who were also aware of the notion of "space behind the mandible." The second had been described previously, ${ }^{4}$ and could easily be interpreted as "space below the mandible." Normal laryngoscopy, performed using a traditional rigid blade, consists, in part, of displacing the tongue to one side. The tongue is the only obstacle to a direct view of the larynx and its disposition is critical. Inevitably, there will be a certain volume of the tongue not moved to one side, an "inevitable residual volume" (IRV). This mass must be accommodated when the blade is drawn forward to expose the larynx. It can either remain between the blade and the mandible or in the space immediately below the mandible. This explains how the two elements are related.

Before laryngoscopy the tongue is essentially in the mouth and the hyoid lies parallel to and just below the lower border of the mandible posteriorly. The insertion of a curved blade for laryngoscopy results in contact between the blade tip and the hyoid bone. The hyoid bone is displaced anteriorly and downwards towards the larynx. It is also rotated on its body causing the greater horns to turn upwards. The IRV is accommodated between the blade and the mandible and the space immediately below it (Figure 1). This represents a shift of a substantial part of the tongue below the level of the mandible.

When intubation is moderately difficult, positioning the blade may be a problem because the space behind the mandible is limited and the IRV reduced. A larger proportion of the tongue than normal is pushed into the

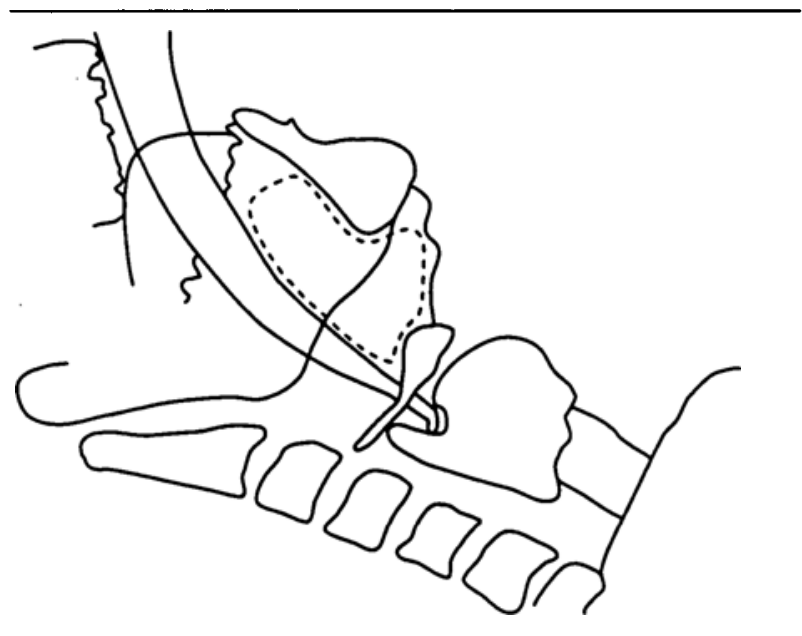

FIGURE 2 Diagram derived from an $x$-ray larynogscopy of a patient known to be a difficult intubation. Details of the base of the tongue and epiglottis are obscured by the bulk of tissue. The blade is some way from the anterior airway line and there is almost no available space for the IRV. The "pear-shape" of the IRV is characterised by the constriction at the mandible and its flattened inferior surface.

pharynx as a consequence of blade insertion. Contact with the hyoid is initially less likely but then, as the laryngoscope is pulled forward, a wedging effect relative to the mandible develops and still more tongue is forced into the space below. Downward descent of the tongue is held up at the larynx, and the force within it then disseminates radially to limit how far the blade can come forward. That the epiglottis can also appear immobilised against the posterior pharyngeal wall is also explained by this mechanism. The term "peardrop effect"1 has been used to describe the effect on the tongue and the resulting change in its shape (Figure 2).

The area available for accommodating IRV has been described by a mathematical formula. ${ }^{5}$ The number, $F$, represents IRV in a form which makes it independent of a subject's size. It is defined by:

$$
\mathrm{F}=100 \times \mathrm{XT} / \mathrm{IT} \times \mathrm{XS} / \mathrm{JS} \times \sin (\text { Beta })
$$

The relevant geometric reference points are: I - the tip of the upper incisors; $J$ - the mid-point between the mandibular condyles; $\mathrm{S}$ - the internal midpoint of the mandibular symphysis; $T$ - a point on the anterior airway line (the ideal straight line view to the front of the laryngeal inlet ${ }^{6}$ ) level with where the hyoid crosses it during laryngoscopy; Beta is the angle SXT (Figure 1).

The critical variables are XT and SX. Denominators IT and JS make these critical values relative rather than absolute (so that $\mathrm{F}$ is size-independent), while beta is useful when considering the effect of jaw movement. Bedside estimates for $\mathrm{F}$ are possible (though not discussed further 
in this paper), but radiological evaluations are more accurate. Expected normal values for the above ratios are: $\mathrm{XT} / \mathrm{IT}=0.678, \pm 0.024 \mathrm{Sd} ; \mathrm{XS} / \mathrm{JS}=0.223, \pm 0.027$ Sd; Beta $=91.6^{\circ} \pm 5.34 \mathrm{Sd}$. (These values were obtained from ten normal volunteers investigated by " $x$-ray laryngoscopy," i.e., lateral $x$-rays of the head and neck during laryngoscopy. ${ }^{7}$ The measured values were corrected for mouth closure around the blade by rotating the mandible outline about the mid-condylar point until the incisors closed around the laryngoscope. All laryngoscopies were performed using a standardised intubating position, i.e., the neck flexed $35^{\circ}$ and the head extended $15^{\circ}$, relative to horizontal. ${ }^{8}$ )

Clinical experience has shown that intubation becomes difficult for $\mathrm{F}<15$. Values of five and less are associated with serious difficulty and near to zero the "peardrop effect" becomes inevitable, i.e., traditional rigid blade laryngoscopy is inappropriate. The purpose of this paper is to analyse the model mathematically and to determine whether it fits existing clinical concepts, offers new insights, and suggests future lines for investigation.

\section{Methods}

To simplify the trigonometry, angle beta was generally taken to be $90^{\circ}$. A further simplification was to consider the points rotated onto the axes of a Cartesian graph, with $X$ at the origin, JS on the $\mathrm{X}$-axis and IT on the $y$-axis. In reality IT is about $45^{\circ}$ from horizontal. The initial representative measurements derived from the above "standard adult data set" were used as the starting points for the analysis, i.e., XS/JS $-1.9 \mathrm{~cm} / 8.5 \mathrm{~cm}$ (ratio 0.224) and XT/IT $-7.3 \mathrm{~cm} / 10.8 \mathrm{~cm}$ (ratio 0.676).

The drawings and the resulting graphs indicating the type of change studied were annotated similarly (Figure 3). The analysis was based on point displacement by either simple linear translations or rotations or both. Five categories are presented, though these should not be considered exhaustive.

\section{Single variable change}

Variations in length XS (i.e., receding mandible) and changes in angle beta (i.e., normal mouth opening) are examples. Analyses were performed by straightforward substitution in the formula.

\section{Single point plotting for iso-F-values}

If three of the four points, IJTS, remain in their standard set positions it is possible to plot (as "iso-F-values") lines for remaining point at specified F-values. Reference to Figure 3(a) illustrates the technique used. If $T^{\prime}$ is the new position for $T$ and $\mathrm{IT}^{\prime}$ crosses $\mathrm{JS}$ at $\mathrm{X}^{\prime}$, then $\mathrm{SX}^{\prime}$ can be the whole length of JS down to a minimum of zero when $\mathrm{X}^{\prime}$ coincides with $\mathrm{S}$. Starting at $\mathrm{XX}^{\prime}=\mathrm{JX}$

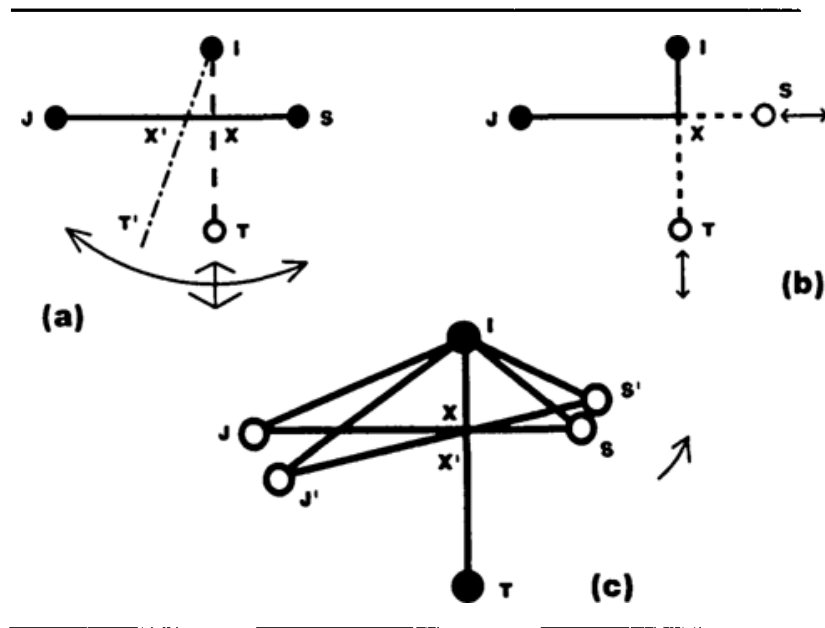

FIGURE 3 The IJST points are rotated onto a Cartesian representation with IT vertical and JS horizontal. Annotations here and in subsequent insets are: $A$ solid bold line - $a$ line of fixed length. Long dashed line - a line of variable length. Solid dots - points which do not move. Open dots - points which can move. Double-ended arrows - independent point movements. Single-ended arrows - points moving along with other points. Various other dotted lines - potential new line positions. In diagram (a) $T^{\prime}$ is the new position (rotated about I) for $T$, with length IT' dependent on the specified F-value (Appendix A). In (b) points IJX are fixed with $S$ and $T$ values investigated so as to plot iso-F-value lines (Appendix B). (c) has rotation of triangle JIS about I to the new position J'IS'. F-values are calculated for the degree of rotation (Appendix C).

and working to $\mathrm{XX}^{\prime}=-\mathrm{SX}$, for given $\mathrm{F}$-values, the positions for $T^{\prime}$ were determined. (Geometric details for computations are outlined in Appendix A.)

\section{Two point changes}

Beta was considered constant. Two adjacent points, say $\mathrm{J}$ and $\mathrm{I}$, were also considered constant, and for specified $\mathrm{F}$-values, the iso-F-value lines (in this case to plot XS versus XT) were computed via the formula (see Figure 3(b) and Appendix B).

\section{Rotating triangles at their apices}

In this analysis, points IJST all started in their set positions, one remained stationary while the others formed a triangle of constant size which was investigated for the effect of rotation about each of its vertices (see Figure 3(c)). The results were plotted for $F$-value against degrees of rotation (Appendix C).

\section{Independent three point changes}

Three dimensional surfaces were constructed from 2variable contour lines. Initial restricting assumptions were necessary to describe the situation under consideration. For XS v XT v JX, IX and beta were assumed constant (Appendix D). 


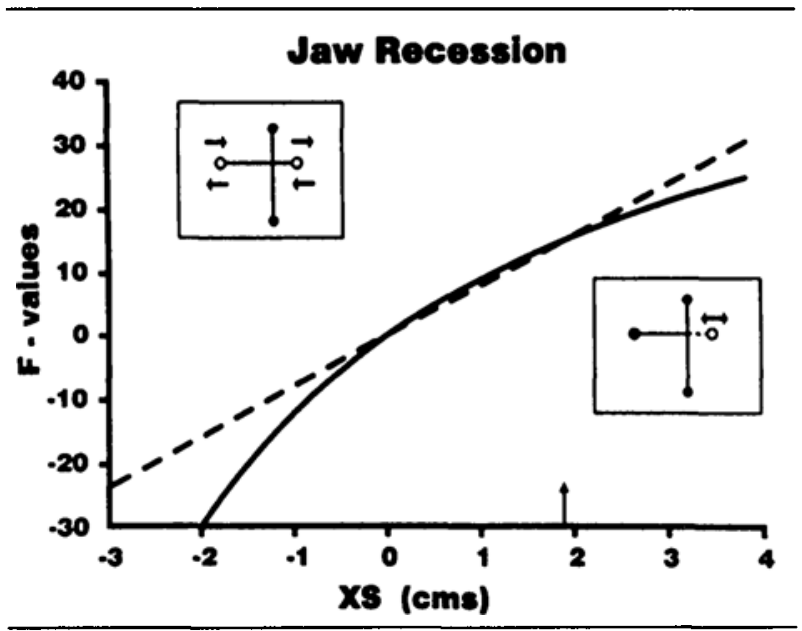

FIGURE 4 Two models of jaw recession are shown. First (upper inset; dotted line graph) a jaw of fixed length is simply moved backwards and forwards relative to IT. The more obvious receding jaw model (lower inset; bold line graph) has point J fixed and length JS varied.

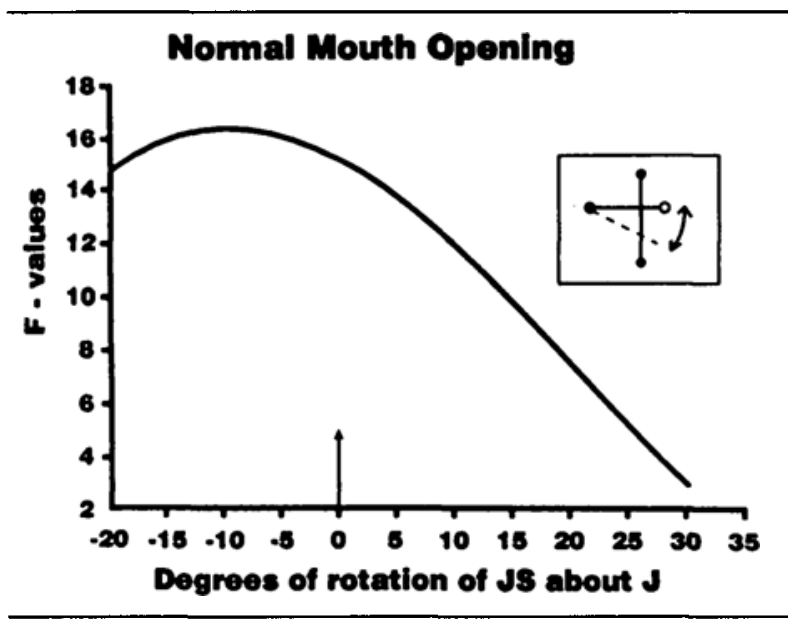

FIGURE 5 Normal mouth opening is represented by assuming the jaw is pulled forward maximally so point $\mathbf{S}$ simply rotates about $\mathbf{J}$. Zero degrees, is the set position, i.e., with the mouth closed around a Macintosh blade. Increased mouth opening moves $\mathrm{S}$ nearer to IT. F $<5$ occurs at $26^{\circ}$.

\section{Results}

\section{Single variable change}

In Figure 4 two graphs are superimposed. With length JS assumed constant and $\mathrm{S}$ further forward or backward relative to IT, the change in F-value versus XS is linear (i.e., dotted line; upper inset). If the position of $\mathrm{J}$ remains constant and XS changes because the length JS changes, the plot is curvilinear (i.e., solid line; lower inset).

Mouth opening plotted against F-values is shown in Figure 5. The value of $F$ decreases slowly at first, then

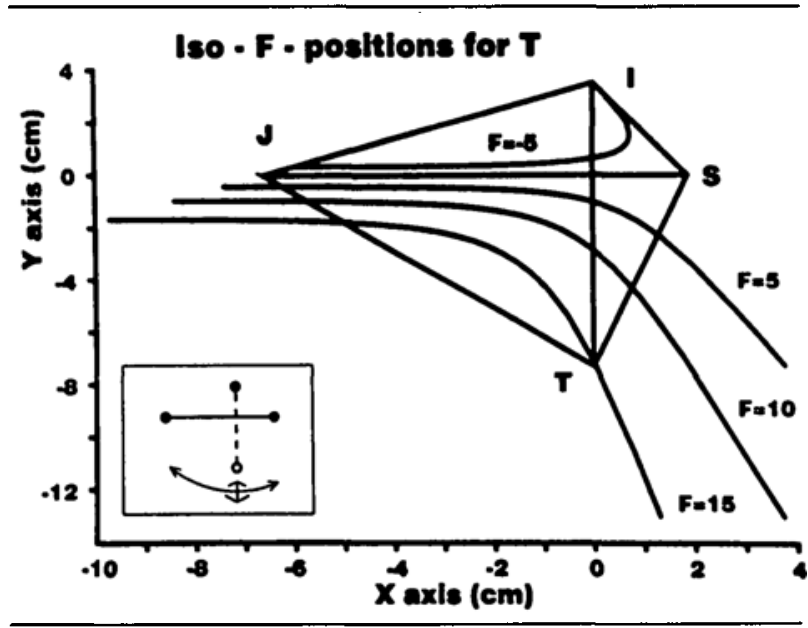

FIGURE 6 If the points $\mathrm{I}, \mathrm{J}$ and $\mathrm{S}$ all remain in their set positions $\mathrm{F}$ values for possible $T$ positions can be plotted. A negative F-value plot is shown for completeness. Positive F-values are asymptotic curves and values after the asymptotes are ignored.

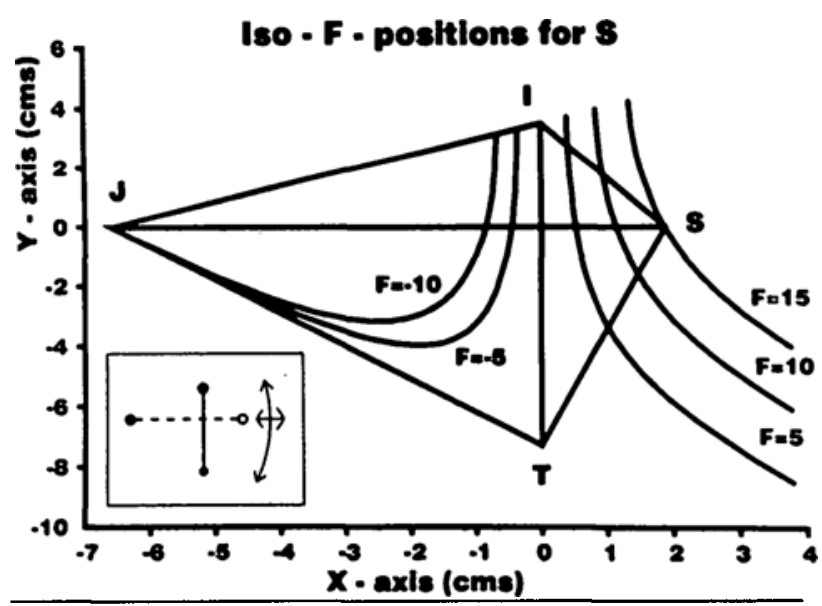

FIGURE 7 Points J, I and $\mathrm{T}$ are set and F-value plots for $\mathrm{S}$ are shown. Asymptotic curves again occur with positive F-plots and values beyond the asymptotes are ignored.

decreases more rapidly. It decreases to $F=5$ only after $25^{\circ}$ rotation. Note that "zero degrees" is equivalent to $2.5 \mathrm{~cm}$ of mouth opening and another $25^{\circ}$ could add a further $3.7 \mathrm{~cm}$ more.

\section{Single point plotting for iso-F-values}

The iso-F-values for single point displacement of $T, S$ and $I$ are illustrated in Figures 6 to 8 respectively. In the simpler case of $I$, each F-value gives a continuous line for the whole range of variable change (i.e., from $X^{\prime} X=-6.6$ to +1.9 ). Figure 8 indicates that if $I$ is positioned slightly more forward than normal, a decrease in F-value occurs. It would, however, need a forward 


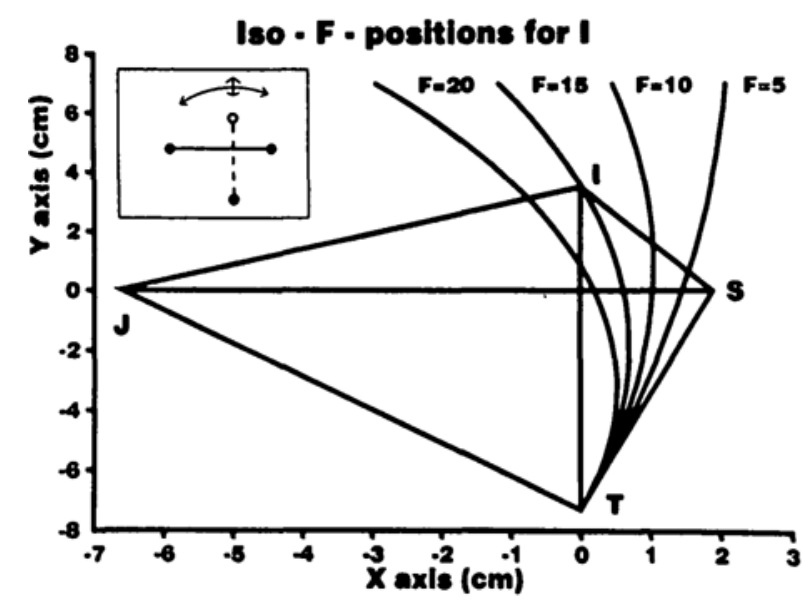

FIGURE 8 Points $\mathrm{T}, \mathrm{S}$ and $\mathrm{J}$ are set, and F-value plots for $\mathrm{I}$ are shown. Positions near to and below JS are again shown for mathematical, not clinical, relevance.

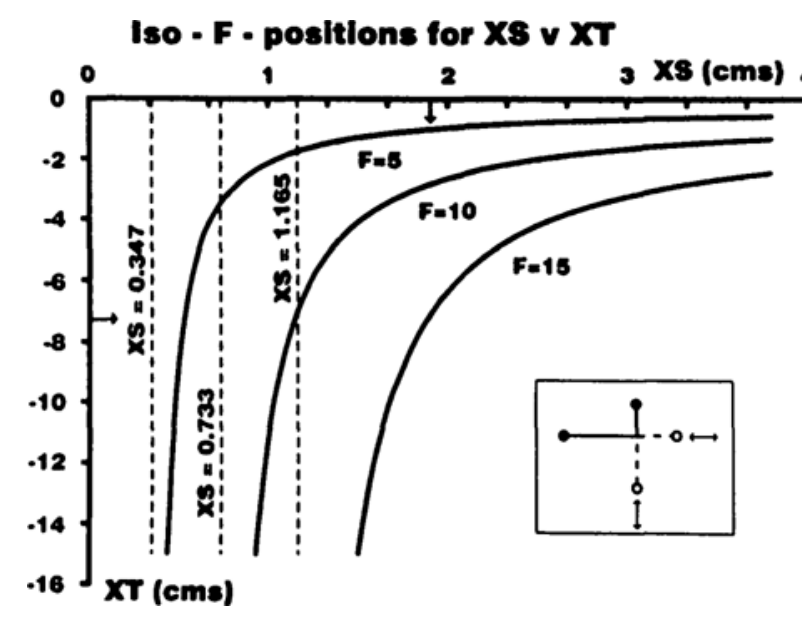

FIGURE 9 Here $\mathrm{J}, \mathrm{X}$ and $\mathrm{I}$ are set with variable $\mathrm{XS}$ and $\mathrm{XT}$ values. The F-value plots are asymptotic curves and the dotted lines are the respective asymptotes.

movement of about $1.5 \mathrm{~cm}$ to change the F-value to 5 . Similar plots for $\mathrm{T}$ and $\mathrm{S}$ are non-continuous on positive F-values because asymptotic behaviour occurs. If values beyond the asymptotes are ignored (as is usual practice for this sort of applied mathematical model) the pattern of iso-F-plots is obviously a continuous series to the negative $\mathrm{F}$-values.

\section{Two point changes}

Figure 9 shows iso-F-value plots for XS against XT. This result requires triangle IXJ to have remained constant and beta at $90^{\circ}$. Figure 10 is a composite of all the possible individual adjacent point graphs. (Each quadrant has its own defining constraints.) Similar exercises with

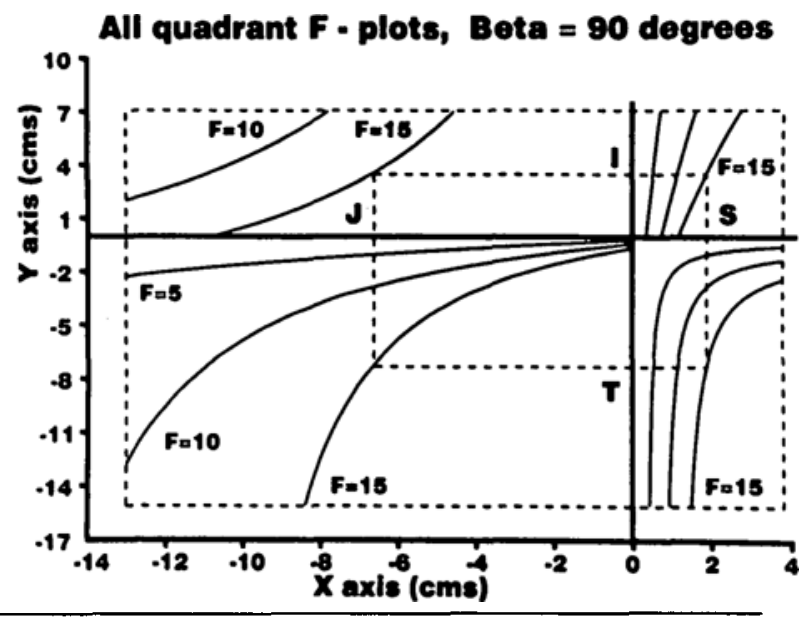

FIGURE 10 This Figure is a composite of the four separate graphs representing individual quadrants, each the equivalents of Figure 9, i.e., containing plots for relevant axial pairs. The central dotted rectangle passes through each axis at the set values. The outer rectangle is at twice these values.

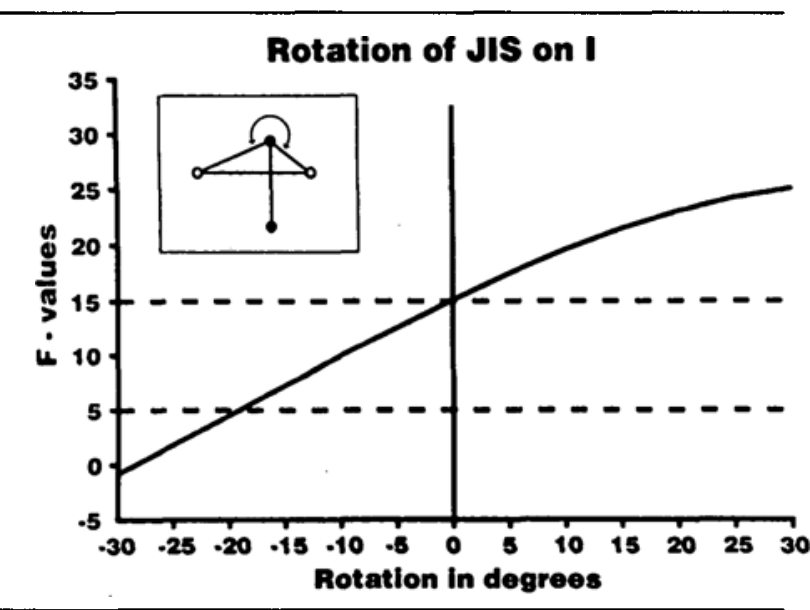

FIGURE 11 T is fixed and JIS is rotated about I. (Positive angles signify anticlockwise rotation.) $F=5$ after just $19^{\circ}$ of clockwise rotation. This represents the clinically important "Hi-slung mandible" (see Figure 12 and text).

beta constant at values other than 90 degrees are also possible.

\section{Rotating triangles at their apices}

Figure 11 describes the most important clinical example of triangular rotation where JIS is rotated about I and point $\mathrm{T}$ remains stationary. At $19^{\circ}$ rotation of $\mathrm{J}$ upwards (i.e., clockwise rotation) the F-value becomes critical. This implies a mechanism for difficulty which has not been described previously. Under standard conditions beta is at $90^{\circ}$ when the mouth is closed around the blade. When the $\mathrm{J}$ position is higher than normal, with the 
TABLE I Summary of clinical interpretations

\begin{tabular}{|c|c|c|c|}
\hline Clinical condition & Figures & Critical values $(F=5)$ & Comment \\
\hline Receded jaw & $4,7,9,10$ & $\begin{array}{l}\mathrm{XS}=0.53 \mathrm{~cm}(\mathrm{XS} / \mathrm{JS}=0.074) \\
(\text { Less if small IX or big XT) }\end{array}$ & $\begin{array}{l}\text { Recession and poor forward translation } \\
\text { comparable in effects. }\end{array}$ \\
\hline $\begin{array}{l}\text { Buck teeth } \\
\text { (or prominent maxilla) }\end{array}$ & 8,10 & I moved forward $1.9 \mathrm{~cm}$ & $\begin{array}{l}\text { Buck teeth unlikely sole cause of difficulty. } \\
\text { Prominent maxilla compares with recessed jaw. }\end{array}$ \\
\hline Edentulous & 8,10 & $\begin{array}{l}\text { I moved back } 1 \mathrm{~cm} \text { allows: } \\
\text { New critical } X S=0.15 \mathrm{~cm}\end{array}$ & $\begin{array}{l}\text { Edentulous patients protected from difficulty due } \\
\text { to jaw recession or anterior larynx. }\end{array}$ \\
\hline "Anterior larynx" & $6,9,10$ & $\begin{array}{l}\text { T moved forward } 3.8 \mathrm{~cm} \\
\text { (Much less if XT is big) }\end{array}$ & $\begin{array}{l}\text { Unlikely sole cause of difficulty. } \\
\text { (Different from peardrop effect when blade is } \\
\text { posterior and larynx seems "anterior"). }\end{array}$ \\
\hline "Hi-slung mandible" & $(5), 11,12$ & JIT increased $19^{\circ}$ (i.e., $\geq 81^{\circ}$ ) & $\begin{array}{l}\text { Possible as sole cause of difficulty or } \\
\text { consequence of limited head extension. }\end{array}$ \\
\hline Short neck & $6,10,13$. & Not limiting of itself & $\begin{array}{l}\text { Exaggerates any tendency to receded jaw or } \\
\text { anterior larynx. }\end{array}$ \\
\hline Normal mouth opening & $5,9,10$ & $\begin{array}{l}25^{\circ} \text { beyond set position } \\
\text { (i.e., mouth open to } 6 \mathrm{~cm} \text { ) }\end{array}$ & $\begin{array}{l}\text { Unlikely laryngoscopy position. } \\
\text { Easier to pull tongue out if mouth widely open. } \\
\text { (Model conditions then invalidated.) }\end{array}$ \\
\hline
\end{tabular}

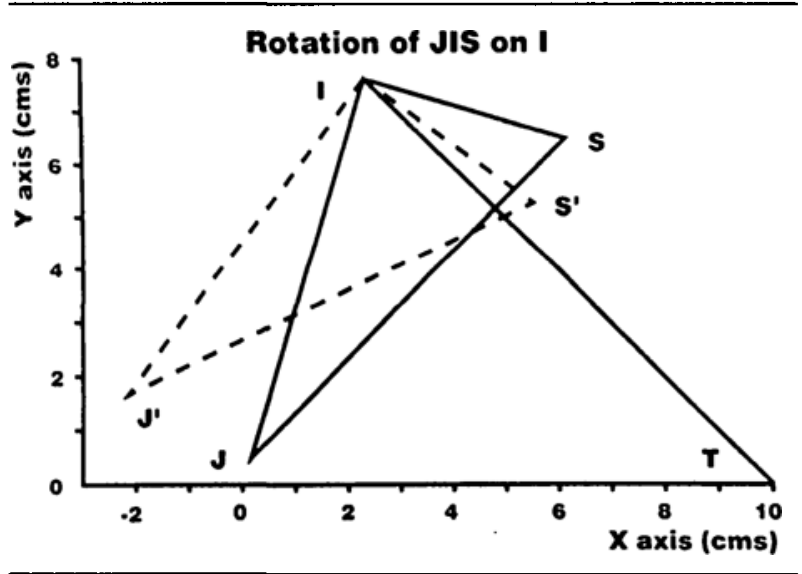

FIGURE 12 When JIS is rotated on I, S comes closer to the line IT. The diagram shows the set position and a rotation of just over $20^{\circ}$ clockwise.

length of JS unchanged, beta is already much $\angle 90^{\circ}$ after the blade is inserted. As a result XS has also decreased markedly. This is further illustrated in Figure 12. The normal jaw only moves close to IT with very wide mouth opening, but in this situation rapid movement toward IT occurs as soon as mouth opening commences.

\section{Independent three point changes}

The horizontal contour lines making up the surface in Figure 13 are equivalents of the JX/XT quadrant in the composite graph of Figure 10, for varied values of XS. This surface for $F=15$ is a relatively simple shape. That for $F=5$ is similar but adheres closely to the $J X$ axis and slopes away from it more rapidly. The gentle sloping reflects the relative unimportance of $\mathrm{JX}$ under these conditions (i.e., IX constant and beta $=90^{\circ}$ ).

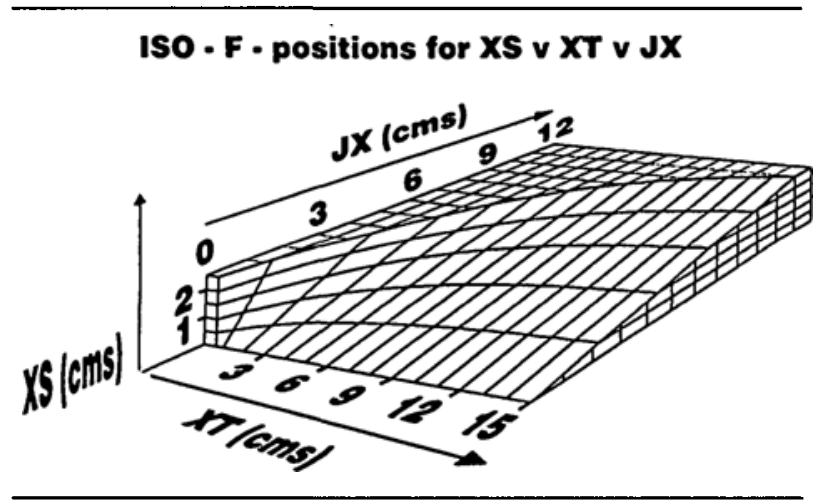

FIGURE 13 This represents a 3-dimensional "surface" plot constructed from contours (Appendix D). The surface represents $F=15$.

Table I summarizes the quantitative clinical implications of these results.

\section{Discussion}

The receded jaw analysis indicates that there is little difference between situations where the jaw is simply considered as receded (i.e., JX remains constant and XS decreases) compared with one that does not protrude forward normally (modelled by JS remaining constant while $\mathrm{XS}$ decreases). By comparison with values previously suggested for difficulty by the "ease of intubation angle"1 (moderate difficulty occurs when angle SIT is $<9^{\circ}$ ), an $\mathrm{XS}$ of $0.6 \mathrm{~cm}$ would be equivalent to an angle of $8.5^{\circ}$ and $\mathrm{F}$-value $<5$.

Mouth opening tends to decrease the F-value but this would need to be extreme to be considered critical. In a series of 200 patients, the mean value for maximum mouth opening was $3.89 \pm 0.65 \mathrm{cms}^{9}$ Only one patient 
had a maximum mouth opening of $6 \mathrm{~cm}$. Even if wide mouth opening was practised as part of a laryngoscopy technique (and observations of clinical practice ${ }^{8}$ suggests this is not the case) such values would be extremely unlikely. Obviously the model supports the notion that there are advantages in closing the mouth around the blade. If it were possible to decrease mouth opening to less than that required for a Macintosh blade, an improved view would be expected. The Bizzarri-Giuffrida blade used such a modification to do away with the "vertical component" of the Macintosh blade. ${ }^{10}$

The single point iso-F-position analyses are as expected. Negative iso-F-values for $T$ are included for analytical completeness only since it is clinically unimaginable for the anterior airway point to be above the level of the mandible. Negative iso-F-values for $\mathrm{S}$, however, indicating extreme jaw recession, do seem feasible. IsoF-values for I show that forward movement of I (as with prominent maxilla or buck teeth) decreases $F$. but not markedly. The value of $F$ increases, as expected, when I moves backward (as for the edentulous state).

The two point positioning indicates the critical nature of the XS distance relative to XT, which the asymptotic behaviour underlines. The composite graph, Figure 10, indicates that the length of JX relative to either IX or $\mathrm{XT}$ is relatively unimportant (under the stated conditions). As for XS v XT, so XS is also of much greater importance than IX. As stated, this exercise can be repeated for alternative values for beta, when similar four quadrant displays result. Because the formula contains the term $\sin$ (beta), and because beta is normally about $90^{\circ}$, it takes a moderate change in beta alone to influence the F-value. (A decrease to $70^{\circ}$ for example would only give a $6 \%$ decrease since $\sin \left(70^{\circ}\right)=0.94$ ).

Perhaps the most interesting and unexpected finding relates to the triangular rotation example which depicts a mechanism for difficulty not described previously, the "hi-slung mandible." When the jaw is opened and pulled forward it initially rotates away from the anterior airway line until beta $=90^{\circ}$. (The expected position for the mouth closed around the blade.) As has been implied in Figure 5, rotating the jaw open more than this brings the symphysis back toward the anterior airway line. When the $\mathbf{J}$ position is higher than normal, however, the jaw starts off with a much reduced beta so this movement back toward the anterior airway line occurs earlier. The rapid decrease in XS is already well under way by the time the blade is inserted into the mouth and this is equivalent to a shift to the left of the normal mouth opening curve (i.e., Figure 5).

The mathematical model should be seen as no more than a hypothesis that has been demonstrated to be consistent with usual clinical observations of what causes difficulty with intubation. The $x$-ray laryngoscopy studies on which it is based ${ }^{1,7,11}$ represent the only attempt to relate degree of difficulty to particular radiological indices for the moment of laryngoscopy performed under standard conditions. These are unlikely to be repeated in much larger series because of radiological exposure to the anaesthetist. The relatively small size of the database is important but full validation of the implications from the model would require further work. Considerable overlap with the main findings of the larger series of conventional $x$-rays of patients reported by Bellhouse and Dore ${ }^{3}$ is relevant.

Model validation is also important because the standard data set used for this analysis is easily replaced in the spreadsheet analyses outlined by alternative data sets. This may prove to be the most useful way of looking at changes associated with difficulty in different age groups. At the same time, the model also indicates that a large number of factors must be taken into account before such work is undertaken. This has already been implied in the work by Williams et al. who reported different incidences of difficulty from different anaesthetists in the same institution with roughly similar groups of patients. ${ }^{12}$

The standardised intubating position described previously ${ }^{8}$ should now be seen as inadequate because the degree of mouth opening is at least as important as the head and neck position. It is obviously reasonable to standardise on a position with the mouth closed around a Macintosh curved blade. Radiological experience has also shown that laryngoscopy may tilt or lift the larynx forward off the cervical vertebrae and this should be standardised by keeping the larynx pressed back against the cervical vertebrae. An epiglottis which is unduly long may also have a disproportionate effect on the view obtained. This can be overcome by standardising the blade position to below the epiglottis. A photographic method which makes accurate recording of the view at laryngoscopy feasible has been described. ${ }^{13}$ These suggested requirements are summarised in Table II.

The analysis of the model shows that it not only fits with many of the ideas of what causes difficulty but, for the first time, gives some indication of how contributing factors can be quantified. In certain situations some factors will increase the likelihood of difficulty but there may coexist features that mitigate against this. For example, iso-F-plots for $\mathrm{T}$ indicate that an anterior larynx would tend to be a disadvantage though it would need to be about $3.8 \mathrm{~cm}$ forward of the normal position to have a serious effect in its own right. Note that "anterior laryn $x^{\prime}$ in this sense is a true forward movement of $T$ relative to the standard data set. This must now be clearly differentiated from the usual clinical concept of an ap- 
TABLE II Requirements to standardise laryngoscopy studies

\begin{tabular}{|c|c|}
\hline Requirement & Comment \\
\hline $\begin{array}{l}1 \text { Standardised } \\
\text { intubating position }\end{array}$ & $\begin{array}{l}\text { Positioning should be monitored during } \\
\text { laryngoscopy as it tends to be altered. }\end{array}$ \\
\hline $\begin{array}{l}2 \text { Controlled mouth } \\
\text { opening }\end{array}$ & $\begin{array}{l}\text { Mouth should be closed around blade. } \\
\text { Corrections afterwards possible for } x \text {-rays. }\end{array}$ \\
\hline $\begin{array}{l}3 \text { Blade used and } \\
\text { technique }\end{array}$ & $\begin{array}{l}\text { Blade determines mouth closure position. } \\
\text { Techinique must be consistent. }\end{array}$ \\
\hline $\begin{array}{l}4 \text { Controlled position } \\
\text { of larynx }\end{array}$ & $\begin{array}{l}\text { Avoid larynx being tilted or pulled forward } \\
\text { by holding it back against vertebrae. }\end{array}$ \\
\hline $\begin{array}{l}5 \text { Allowance for very } \\
\text { long epiglottis }\end{array}$ & $\begin{array}{l}\text { Blade tip positioned below the epiglottis for } \\
\text { consistency. }\end{array}$ \\
\hline $\begin{array}{l}6 \text { Accurate record of } \\
\text { view }\end{array}$ & $\begin{array}{l}\text { Feasible using photographic techniques (see } \\
\text { text). }\end{array}$ \\
\hline
\end{tabular}

parently "anterior" larynx. With the peardrop effect described above it is not necessary for the larynx to be abnormal in position for the blade to be pushed backwards. When it is, the larynx inevitably appears anterior relative to the blade. Radiological assessment of relevant indices, rather than clinical judgement, are required to determine whether the larynx is actually anterior or not.

In general a long neck will tend to mitigate against difficulty associated with a truly anterior larynx, while a short neck will mean this becomes a problem more readily. An interaction of relevant factors is generally to be expected. This explains why it is easy to anticipate, on clinical grounds, that intubation will be difficult when it turns out not to be and more importantly when difficulty occurs without such warning. There is also a suggestion that current patterns of clinical assessment will miss important factors and that better prediction of difficulty is feasible.

The main lesson is that single factors only rarely account for difficulty; more often it is a combination of factors that matter. For example, a protruding maxilla of itself would have little effect (unless $>1.9 \mathrm{~cm}-$ see Table I) but a lesser protrusion combined with any tendency to jaw recession would magnify the effect. This is in keeping with a less commonly quoted radiological survey which concluded "no specific anatomical factor determines the ease of direct laryngoscopy, but a combination of anatomical factors determines the ease of intubation." ${ }^{14}$ It should be realised that the model relates only to two dimensional aspects of intubation and the third dimension will need to be added to the model later. It is tempting to conclude, on the basis of the analysis, that the main questions may already have been answered and that adding the third dimension will be "icing on the cake."

It is particularly pleasing to find that the model indicates a previously undiscovered mechanism for diffi- culty and clinical evidence confirms that this mechanism does occur. When trying to put in place a mechanism to explain nearly all causes of difficulty one that never agreed with the rest was a high-arched palate. Cass et al. suggested this occurs in association with a long narrow mouth. ${ }^{15}$ It now seems reasonable to suggest, however, that if the palate is high it could be that the condyles are more rostral than usual and such subjects might be particularly prone to the "hi-slung mandible." When this mechanism was first discovered the condition was thought to be rare but it may prove to be a relatively common cause of difficulty. In fact increased angle JIT was one of the factors described as being associated with difficulty in an earlier paper.'

No mathematical model for a biological system should be considered to be applicable for all possible values, especially when the mathematical extremes are considered. However, it has been shown that this model appears to be mathematically well behaved over the likely clinical ranges. Further clinical investigation at target areas highlighted by the model can be expected to be used to test its accuracy and predictions. For example, in a given individual it should be possible to record the view obtained at laryngoscopy under standard conditions and then repeat the observations with altered variables and determine whether the change is predicted by the model. For example, it should be possible with various dental prostheses to alter the position of I and or S.

It is suggested that this model will help in the understanding of the factors considered in difficult intubation.

\section{Acknowledgements}

The author would like to express his particular appreciation to the following colleagues who have helped with the work: Dr. K. Wilkinson, Dr. W.A. Horton, Dr. L. Fahy, Dr. P.J. Singh, Dr. I. Tweedie, Dr. N. Seth and most recently Mr. R. Hancock and Dr. R.R.D. Marks. The author will be happy to make available the full geometrical analyses for those wishing to use their own data sets or to construct their own spreadsheets.

\section{Appendices}

\section{A Iso-F-positions, e.g., for $T$}

In Figure 3(a), the initial position for IXT is as for the standard data set. For a given starting F-value the new $\mathrm{IX}^{\prime} \mathrm{T}^{\prime}$ positions will be plotted for $\mathrm{XX}^{\prime}$ values from $\mathrm{XX}^{\prime}$ $=J X$ to $X^{\prime}=-X S$. $\left(X^{\prime}\right.$ remains on the line JS, whatever the position of $T^{\prime}$.)

Since IXX' is a right angle triangle and IX is constant, for any $\mathrm{XX}^{\prime}$ we can determine angle IX' $\mathrm{X}$ and length IX'. 
Beta' is $180-\mathrm{IXX}$ degrees.

$\mathrm{SX}^{\prime}=\mathrm{SX}+\mathrm{XX}^{\prime}$

Since $\mathrm{F}=100 \times \sin (\beta) \times \mathrm{X}^{\prime} \mathrm{T}^{\prime} \times \mathrm{SX}^{\prime} /\left(\mathrm{JS} \times\left(\mathrm{IX}^{\prime}\right.\right.$ $+X^{\prime} T$ )) for any required $F$ value we can find $X^{\prime} T^{\prime}$ which allows the required plot. (Cartesian conversion is required to allow $\mathrm{T}$ to be plotted but this should be straightforward.)

B Two point changes, e.g., $X S$ versus $X T$

(See Figure 3(b)). XI, JX and beta are taken as known and constant. For any given $\mathrm{F}$-value, the only variables in the remaining in the formula are XS and XT, so one can be plotted directly against specific values of the other.

\section{Triangular rotations, e.g., JIS on I}

In Figure 3(c) let SIS' represent an external anticlockwise rotation of triangle JIS about $\mathrm{I}$, and $\mathrm{J}^{\prime} \mathrm{IS}^{\prime}$ the new position for the triangle. $\mathrm{X}^{\prime}$ is where $\mathrm{J}^{\prime} \mathrm{S}^{\prime}$ crosses IT. The new value for beta, beta $=90^{\circ}+$ SIS'$^{\prime}$. By the sine rule:

$$
\begin{aligned}
& \mathbf{S}^{\prime} \mathbf{X}^{\prime}=\mathrm{IS}^{\prime} \times \sin (\mathrm{XIS}+\mathrm{SIS}) /\left(\sin \left(180-\mathrm{S}^{\prime} \mathbf{X}^{\prime} \mathrm{T}\right)\right) \text { and } \\
& \text { IS' }^{\prime}=\text { IS } \\
& \mathrm{X}^{\prime} \mathrm{T}=\mathrm{IT}-\left(\mathrm{IS}^{\prime} \times \sin \left(\mathrm{IS} \mathbf{X}^{\prime}\right) / \sin \left(180-\mathrm{S}^{\prime} \mathrm{X}^{\prime} \mathrm{T}\right)\right)
\end{aligned}
$$

These new values are then substituted directly into the formula since IT and JS remain constant.

D Three point change, e.g., $X S \vee X T \vee J X$

Here IX and beta are assumed constant.

If $C=F /(100 \times \sin (\beta))$ and $K=I X$, then for

$\mathrm{X}=\mathrm{XS} ; \mathrm{Y}=\mathrm{XJ} ; \mathrm{Z}=\mathrm{XT}$

$\mathrm{C}=\mathrm{XZ} /((\mathrm{X}+\mathrm{Y}) \times(\mathrm{Z}+\mathrm{K}))$

For any given $\mathrm{F}$-value a contour can be plotted by holding one variable constant (e.g., XS = 2) the other two can be plotted one against the other. The contours can be built up to construct a surface plotting. Figure 13 shows such a surface for $F=15$.

\section{References}

1 Horton WA, Fahy L, Charters $P$. Factor analysis in difficult tracheal intubation: laryngoscopy-induced airway obstruction. Br J Anaesth 1990; 65: 801-5.

2 Frerk CM. Predicting difficult intubation. Anaesthesia 1991; 46: 1005-8.

3 Bellhouse CP, Doré C. Criteria for estimating likelihood of difficulty of endotracheal intubation with the Macintosh laryngoscope. Anaesth Intensive Care 1988; 16: 329-37.

4 Patil VU, Stehling LC, Zaunder HL. Fibreoptic Endoscopy in Anesthesia. Chicago: Year Book Medical Publishers, 1983.

5 Horton WA, Fahy L, Charters P. Towards a single index for quantifying osseous factors in difficult laryngoscopy (Abstract). Br J Anaesth 1990; 65: 583-4P.

6 Marks RRD, Hancock $R$, Charters $P$. An analysis of laryngoscope blade shape and design: new criteria for laryngoscope evaluation. Can J Anaesth 1993; 40: 262-70.

7 Horton WA, Fahy L, Charters P. Disposition of cervical vertebrae, atlanto-axial joint, hyoid and mandible during X-ray laryngoscopy. Br J Anaesth 1989; 63: 435-8.

8 Horton WA, Fahy L, Charters $P$. Defining a standard intubating position using "Angle Finder". Br J Anaesth 1989; 62: 6-12.

9 Charters $P$, Wilkinson $K$. Tactile orotracheal tube placement test. A bimanual tactile examination of the positioned orotracheal tube to confirm laryngeal placement. Anaesthesia $1987 ; 42: 801-7$.

10 Bizzarri DV, Giuffrida JG. Improved laryngoscope blade designed for ease of manipulation and reduction of trauma. Anesth Analg 1958; 37: 231-2.

11 Fahy $L$, Horton WA, Charters $P$. Factor analysis in patients with a history of failed tracheal intubation during pregnancy. Br J Anaesth 1990; 65: 813-5.

12 Williams $K N$, Carli F, Cormack RS. Unexpected, difficult larynogscopy: a prospective survey in routine general surgery. Br J Anaesth 1991; 66: 38-44.

13 Hancock $R$, Patel $B C$. Clinical photoghraphy: a method of accurate documentation. J Audiov Media Med 1989; 12: 154-5.

14 Van der Linde JC, Roelofse JA, Steenkemp EC. Anatomical factors relating to difficult intubation. S Afr Med J 1983; 63: 976-7.

15 Cass NM, James NR, Lines $V$. Difficult direct laryngoscopy complicating intubation for anaesthesia. B M J 1956; 1: 488-9. 